\title{
High-frequency asymmetric volatility connectedness between Bitcoin and major precious metals markets
}

\author{
Walid Mensi ${ }^{\mathrm{a}, \mathrm{b}}$, Ahmet Sensoyc, Aylin Aslan ${ }^{\mathrm{c}, \mathrm{d}}$, Sang Hoon Kang,e,f, \\ ${ }^{a}$ Department of Finance and Accounting, University of Tunis El Manar, Tunisia \\ ${ }^{\mathrm{b}}$ Department of Economics and Finance, College of Economics and Political Science, Sultan Qaboos University, Muscat, Oman \\ ${ }^{\mathrm{c}}$ Faculty of Business Administration, Bilkent University, Ankara 06800, Turkey \\ ${ }^{\mathrm{d}}$ Statistics Department, Central Bank of the Republic of Turkey, 06050, Ulus, Ankara, Turkey \\ e Department of Business Administration, Pusan National University, Busan 609-735, Republic of Korea \\ ${ }^{\mathrm{f}}$ School of Commerce, University of South Australia, Australia
}

\section{A R T I C L E I N F O}

\section{JEL classification}

G14

G15

\section{Keywords:}

Bitcoin

Precious metals

High frequency

Asymmetric volatility connectedness

\begin{abstract}
A B S T R A C T
This study examines the asymmetric volatility connectedness between Bitcoin and major precious metals markets (gold, silver, palladium, and platinum). We use high-frequency data with methodologies introduced by Diebold and Yilmaz (2014) and Baruník, Kočcenda, and Vácha (2017). The results show evidence of significant volatility spillover effects between Bitcoin and precious metals. Moreover, the risk spillovers vary over time and are sensitive to slowdowns in economic activity and political events (e.g., the Brexit vote and the US presidential election). Palladium is the largest net contributor of spillovers while Bitcoin is a net recipient. Finally, evidence of asymmetry in semi-volatility transmission shows that Bitcoin heavily transmits netpositive spillovers to other assets. The results of our research are of interest and importance to investors, portfolio managers, and policy-makers, as the results can readily inform their decisionmaking.
\end{abstract}

\section{Introduction}

The last decade was marked by increasing integration of international markets, which has resulted in crashes and financial crises, including the global financial crisis in 2008 and the European debt crisis in 2012. The increase in cross-market linkages or spillovers has increased portfolio riskiness and decreased diversification benefits, pushing investors and portfolio managers to find alternative assets that help to hedge exposure risk. Precious metals, particularly gold, palladium, platinum, and silver, constitute good alternatives for hedging because of their low correlation with other financial and commodity assets (such as stocks, currency bonds, and oil markets) and the safe-haven asset characteristics that they may provide in periods of financial turmoil (Baur \& Lucey, 2010; Baur \& McDermott, 2010; Jensen, Johnson, \& Mercer, 2002; Draper, Faff, \& Hillier, 2006; Canover, Jensen, Johnsos, \& Mercer, 2009; Reboredo \& Rivera-Castro, 2014).

As with precious metals, Bitcoin (BTC) has proven to be resilient during times of distress, ever since it was created in 2009, accentuating its potential role as a hedge and safe haven for financial and commodity markets against rising global uncertainty

\footnotetext{
The views expressed in this work are those of the authors and should not be attributed to the Central Bank of the Republic of Turkey. This paper is a part of Aylin Aslan's Ph.D. thesis in the Faculty of Business Administration in I.D. Bilkent University.

* Corresponding author at: Department of Business Administration, Pusan National University, Busan 609-735, Republic of Korea.

E-mail addresses: walid.mensi@fsegt.rnu.tn (W. Mensi), ahmets@fen.bilkent.edu.tr (A. Sensoy), a.aslan@bilkent.edu.tr (A. Aslan), sanghoonkang@pusan.ac.kr (S.H. Kang).
} 
(Dyhrberg, 2016; Bouri, Azzi, Dyhrberg, 2017; Bouri, Jalkh, Molnár, Roubaud, 2017; Corbet, Meegan, Larkin, Lucey, \& Yarovaya, 2018; Bouoiyour, Selmi, \& Wohar, 2018; Selmi, Mensi, Hammoudeh, \& Bouoiyour, 2018).

BTC is based on a decentralized peer-to-peer network known as Blockchain. It is an unregulated digital currency derived from online mathematical cryptography and recently perceived as a substitute for government-backed currencies. Being one of the most popular cryptocurrencies-now perceived as a new type of financial asset-as well as the largest one, BTC has grown exponentially in value along with the media interest in the phenomenon and the attention it has received in the finance literature. ${ }^{1}$ The literature has considered BTC from different perspectives. While a small group of studies such as Dwyer (2015), Bariviera (2017), and Bariviera, Zunino, and Rosso (2018) examine the technical aspects and stylized facts of BTC, most of the studies focus on whether BTC prices satisfy either the weak or semi-strong forms of the efficient market hypothesis (e.g., Urquhart, 2016; Nadarajah \& Chu, 2017; Bariviera, 2017). Another growing strand of literature specifically considers BTC's return-volatility characteristics (Bouri, Azzi et al., 2017; Peng, Albuquerque, de Camboim, Padula, \& Montenegro, 2018) and whether speculative bubbles occur in the BTC market (Cheah \& Fry, 2015; Corbet et al., 2018). Other studies point out that BTC is viewed as a speculative investment rather than a safe haven or a hedge (Kristoufek, 2013; Yermack, 2014; Molnár, Vagstad, \& Valstad, 2015; Ciaian, Rajcaniova, \& Kancs, 2016) while some works show that this may not necessarily be the case. BTC could be plausibly included in optimal portfolios since it enjoys trust when an economic crisis occurs or when mainstream currencies and assets lose their credibility (Eisl, Gasser, \& Weinmayer, 2015; Popper, 2015; Gangwal, 2016; Baur, Hong, \& Lee, 2018).

Despite growing research on the hedge and safe-haven properties of BTC vis-à-vis major world stock indices, bonds, oil, gold, and the general commodity index, the relationships between BTC and precious metals except gold have so far been ignored. To enrich the related empirical literature, this paper investigates the linkages between BTC and major precious metal markets and its role as a hedge and/or safe haven to protect against similar risks, using five-minute frequency data and the methods developed by Diebold and Yilmaz (2014) and Baruník, Kočcenda, and Vácha (2017).

Our findings can be summarized as follows: (i) We find significant volatility spillover effects among precious metals and BTC. (ii) Moreover, the spillover trend intensified during general periods of slowdown in global economic activity as well as the Brexit vote and the US presidential election, evidencing financial contagion. In terms of net spillovers, palladium is the largest net contributor of spillovers, followed by gold; BTC is a net recipient of spillovers. Evidence of asymmetry in semi-volatility transmission shows that BTC heavily transmits net positive spillovers to other assets. The bad volatility of palladium affects the volatility of other assets more than its good volatility does. On the other hand, the extent of the net spillover of gold is time dependent. We also identify the network of connectedness and posit that palladium has the greatest influence on the good and bad volatility of BTC. Our findings are in line with existing evidence that Bitcoin is a valuable portfolio diversifier (Bouri, Molnár, Azzi, Roubaud, Hagfors, 2017; Bouri, Jalkh et al., 2017; Brière, Oosterlinck, \& Szafarz, 2015; Corbet et al., 2018; Dyhrberg, 2016; Guesmi, Saadi, Abid, \& Ftiti, 2019), which we have extended by considering asymmetric connectedness between positive- and negative-volatility spillovers.

This study adds to the existing literature in four ways. First, it investigates the asymmetric relations between BTC and precious metals such as gold, silver, platinum, and palladium. This analysis would assist investors to determine whether BTC provides a viable alternative to all types of precious metals as a hedger/diversifier. In addition, it would help policy makers and regulatory bodies perceive the role of this digital currency as an investment asset compared to precious metals. Second, instead of using daily data, as most of the previous studies did, we get to the high-frequency level and analyze the relationship between BTC and precious metals at intervals of five minutes. The idea is that algorithmic (especially high-frequency) trading has dominated the trading scene in recent years. In this structure, automated computers are programmed to make rapid decisions in reaction to varying market data in real time (Sensoy, 2018). As of 2012, algorithmic trading constituted $85 \%$ of the total trading volume in US equities, with high-frequency trading strategies (maintaining a long position in an asset for merely a few minutes) representing a big part of this value (Glantz \& Kissell, 2013). Today, algorithmic trading platforms for customers are propelled by several BTC exchanges, requiring an analysis of the relationship between BTC and other assets at the intraday level. However, only a few studies have so far analyzed the BTC market using high-frequency data (Bariviera et al., 2018; Peng et al., 2018). To the best of our knowledge, no previous study has conducted this type of analysis.

Third, the study analyzes daily intraday data for a four-year period that includes both slowdowns in global economic activity and upward trends in growth rates of advanced economies. The sample period also includes crucial events such as the UK's exit from the EU (Brexit) and the US presidential election, which led to uncertainty over the global growth outlook. Such events help us to analyze the dynamics of equicorrelations and volatility spillovers as well as design optimal portfolios and hedging strategies during periods of global economic and political uncertainty. Finally, we apply state-of-the-art methodologies in our analysis, such as Diebold and Yilmaz (2012) generalized spillover index and directional spillover measure, Baruník et al. (2017) methodology for measuring directional spillover asymmetry, and Diebold and Yilmaz's (2014, 2016) methodology for the network topology of market connectedness. The time-varying total volatility spillover index between BTC and precious metals, obtained using dynamic rollingsample analysis, provides useful information on the behavior of volatilities over time. Further, the exploration of the dynamics in the

\footnotetext{
${ }^{1}$ The BTC market is open $24 \mathrm{~h}$ a day and 7 days a week and is rather young. However, with a market capitalization of more than $\$ 112$ billion and a market share of more than $53.8 \%$ in the cryptocurrency world as of October 2018, the role of BTC can no longer be ignored in the financial markets. Futures contracts on BTC have begun to be traded on the Chicago Board Options Exchange (CBOE) as of December 10, 2017, indicating that BTC is now a valid financial asset not only in the eyes of traders, but also policy makers. With these contracts, investors now participate in a regulated marketplace when trading by taking their perceptions of BTC prices into account. The latest move by CBOE has taken the role of BTC in financial markets to a whole new level.
} 
pattern of directional asymmetries helps us see the effect of positive or negative shocks on volatility spillovers.

The remainder of the study is organized as follows. Section 2 reviews the related literature. Section 3 describes the methodology used in this study. Section 4 presents the data and the descriptive statistics. Section 5 discusses the results and their implications for portfolio risk management. Section 6 concludes the paper.

\section{Literature review}

A growing corpus of literature has addressed the spillover effect between financial markets. Information regarding the spillover effect is of particular importance for asset allocations and risk management. Further, the interdependence and contagion among the financial markets provide useful information for rescue measures and is therefore crucial for regulatory authorities and international financial institutions (Shahzad, Xiu, Wan, \& Shahbaz, 2018). Extant empirical studies show, by providing useful insight regarding the relationship between gold and the stock and bond indices of numerous developed countries, that gold is a safe haven for international stock and bond markets (Baur \& Lucey, 2010; Baur \& McDermott, 2010; Coudert \& Raymond, 2011; O'Connor, Lucey, Batten, \& Baur, 2015; Yaya, Tumala, \& Udomboso, 2016; Ji, Bouri, Roubaud, 2018). The role of other precious metals is rarely documented despite their capacity to effectively hedge investment portfolios.

However, more recent studies, including Lucey and Li (2015), Batten, Ciner, and Lucey (2015), and Agyei-Ampomah, Gounopoulos, and Mazouz (2014), emphasize the resilience of the silver, platinum, and palladium markets (along with gold markets) to financial crises and suggest that adding precious metals to a portfolio can lower the systematic risk of investment through diversification, particularly during periods of abnormal equity market volatility (Hillier, Draper, \& Faff, 2006; Belousova \& Dorfleitner, 2012; Skiadopoulos, 2012; Lucey \& Li, 2015).

Mensi, Hamed Al-Yahyaee, and Kang (2017) investigate the time-varying risk spillovers between precious metals and the US, Japanese, European, and Asian stock markets based on the spillover index of Diebold and Yilmaz (2012). They find evidence of spillover effects between the precious metal and stock markets. In addition, they show that all the aforementioned stock markets (except the Japanese market) were key determinants of risk spillovers and the four precious metals markets were net receivers of risk during the global financial crisis and European sovereign debt crisis periods.

Several studies focus on the spillover effects from precious metals to currency and crude oil prices. Antonakakis and Kizys (2015) find, by investigating the dynamic interdependence among returns and the volatility of commodities and currency markets, that the information contents of gold, silver, platinum, and the CHF/USD and GBP/USD exchange rates are the source of returns and volatilities of palladium, crude oil, and the EUR/CHF and GBP/USD exchange rates. In addition, they show that gold and CHF/USD are the leading commodity and currency transmitters, respectively, of return and volatility spillovers to the other assets in their model. Lastly, they note that the results of the dynamic spillover analysis are time- and event-dependent. Similarly, Fernandez-Perez, Frijns, and Tourani-Rad (2017) investigate the contemporaneous spillovers among precious metals (gold, silver, platinum, and palladium), crude oil, and US exchange rates using a structural vector autoregressive (VAR) model. The authors show strong and asymmetric contemporaneous spillovers that are not captured by Granger causality statistics. Hammoudeh and Yuan (2008) also examine a relationship in the form of integrated networks. They analyze the US precious metals market using generalized autoregressive conditional heteroskedasticity (GARCH) models and find that lagged oil prices serve as a determinant of the univariate volatilities of silver, gold, and copper. Huang, Cheng, Guo, and Shao (2012) analyze the effect of the US dollar and oil prices on the Chinese precious metals market (copper, gold, and silver) using a VAR model. They find that the US dollar determines the prices of Chinese gold and silver. Recently, Shahzad et al. (2018) investigate the spillover from international oil prices to a wide array of precious metal (gold, silver, platinum, palladium, and titanium) returns. Implementing the VAR for a value-at-risk (VaR) specification, they examine the upside/downside risk spillovers from oil to the precious metals markets and concurrently measure the response of each precious metal to the expected negative/positive oil shocks.

Another strand in the literature addresses the individual relationships between Bitcoin and other financial assets and highlights the valuable role of Bitcoin as an investment asset. Dyhrberg (2016), Bouri, Molnár et al. (2017), and Bouri, Jalkh et al. (2017) emphasize the benefits of including BTC in portfolios. Dyhrberg (2016) examines the hedging capabilities of BTC with the asymmetric GARCH methodology using daily USD/EUR and USD/GBP exchange rates and the FTSE index for the period July 19, 2010 to May 22, 2015. The author finds that BTC can hedge against the FTSE index and-in the short term-the US dollar. In the same vein, Bouri, Molnár et al. (2017) explore the diversification, hedging, and safe-haven properties of BTC against major world stock indices, bonds, oil, gold, the general commodity index, and the US dollar index by means of a dynamic conditional correlation model. They show, using daily and weekly data, that BTC is appropriate for diversification purposes. However, BTC exhibits a strong safe-haven property in the case of weekly extreme downward movements in Asian stocks. Bouri, Jalkh et al. (2017) also examine, by applying bivariate asymmetric dynamic conditional correlations (DCCs), whether BTC has adopted the role of a diversifier, hedge, or safe haven against both general commodity indices and specific energy commodity indices. Their findings suggest that BTC is considered a strong hedge and a safe haven against both commodity indices.

Bouoiyour and Selmi (2017), using an approach based on ensemble empirical mode decomposition, explore the hedging and safehaven capabilities of BTC for the US stock price index. The results demonstrate that BTC's ability to act as a safe haven depends on time: it works as a weak safe haven in the short run and a hedge in the long run. Corbet et al. (2018) analyze the relationships between three cryptocurrencies (BTC, Ripple, and Litecoin) and a variety of other financial assets such as the MSC GSCI total returns index, the USD broad exchange rate, the SP500 index, the COMEX closing gold price, VIX, and the Markit ITTR110 index. They implement the generalized variance decomposition methodology to assess the connection between cryptocurrencies and the mainstream assets. Their findings indicate that cryptocurrencies are interconnected and may serve as a diversifier that benefits investors in 
the short term. Katsiampa (2018), while investigating the volatility dynamics of Bitcoin and Ether, exhibits evidence of interdependencies in the cryptocurrency market. In addition, the author shows that Ether can be an effective hedge against Bitcoin, while the analysis of optimal portfolio weights points out that Bitcoin should outweigh Ether. Similarly, Ji, Bouri, Lau, and Roubaud (2019) employ a set of measures developed by Diebold and Yilmaz (2012, 2016) to observe connectedness via return and volatility spillovers across six large cryptocurrencies. Regarding volatility spillovers, the results show that Bitcoin has the greatest effect on other cryptocurrencies, followed by Litecoin; Dash exhibits extremely weak connectedness, offering hedging and diversification benefits in the cryptocurrency market. They further reveal that trading volume and global financial and uncertainty effects are determinants of spillovers. In addition, gold prices have a negative effect on net directional-volatility spillovers, whereas VIX shows a positive effect. In the same vein, Aslanidis, Bariviera, and Martínez-Ibañez (2019) study cryptocurrencies and traditional assets (stock and bond indices, and gold). Applying dynamical conditional correlation analysis to the cryptocurrency market, they find positive correlations among cryptocurrencies and negligible correlations between cryptocurrencies and traditional financial assets. An investigation by Canh, Wongchoti, Thanh, and Thong (2019) is one of the recent studies that examine volatility spillovers in the cryptocurrency market. Analyzing the largest seven cryptocurrencies (Bitcoin, Litecoin, Ripple, Stellar, Monero, Dash, and Bitcoin), they document volatility spillovers with strong positive correlations among cryptocurrencies and find limited diversification benefits within the cryptocurrency market. Ji, Bouri, Gupta, Roubaud (2018) question the causal relationships between Bitcoin and several financial assets (i.e., equities, bonds, currencies and commodities) using a directed acyclic graph-based approach and forecast error variance decompositions. Their results indicate that Bitcoin is quite isolated. However, they find evidence of lagged relationships between Bitcoin and some assets, especially during the bearish state of the Bitcoin market.

Bouoiyour et al. (2018) compare the roles of BTC and gold as a hedge, a safe haven, and/or a diversifier against extreme fluctuations in oil prices, using a quantile-on-quantile approach and the conditional VaR measure. The authors find that both BTC and gold reduce oil-related portfolio risks but BTC can serve as a more pronounced hedge and safe haven than gold. Similarly, Selmi et al. (2018) compare the hedging features of Bitcoin and gold against extreme oil price movements, under alternative distributions of both oil and Bitcoin/gold markets. By controlling for various uncertainty proxies, they confirm the usefulness of including both Bitcoin and gold, but not oil, in a portfolio risk management plan during political and economic turmoil. The diversification benefits of BTC are also supported by the recent work of Guesmi et al. (2019). Bouri, Gupta, Lau, Roubaud, Wang (2018) examine daily dependence between global financial stress and Bitcoin by applying various standard and quantile-based copula models. The authors find evidence of directional predictability from the global financial stress index to Bitcoin returns, highlighting Bitcoin's ability to act as a safe-haven against global financial stress for approximately 60 days. Shahzad, Bouri, Roubaud, Kristoufek, Lucey (2019) contribute to the debate surrounding the safe-haven property of Bitcoin proposing a new definition of a weak and strong safe haven within a bivariate cross-quantilogram approach. Their results show that Bitcoin, gold, and the commodity index are weak safe havens in some cases and that the safe-haven roles of those assets are time-varying.

Bouri, Gupta, Lahiani, Shahbaz (2018) study the nonlinear, asymmetric and quantile effects of aggregate commodity index and gold prices on the price of Bitcoin by implementing several advanced autoregressive distributed lag (ARDL) models. The authors suggest the possibility to predict Bitcoin price movements based on price information from commodity and gold prices.

Anyfantaki, Arvanitid, and Topaloglou (2018) assess other cryptocurrencies (Ether, Ripple, and Litecoin), in addition to Bitcoin, in terms of their diversification benefits. They apply stochastic dominance spanning tests with in-sample and out-of-sample data and find that cryptocurrencies provide investment opportunities for risk-averse investors to look beyond traditional asset classes (stocks, bonds, and cash). In their analysis, cryptocurrency markets are segmented from traditional stock and bond markets to explain the domination of the expanded investment universe.

Despite emerging studies on the hedge and safe-haven properties of BTC, their asymmetric interlinkages to precious metals (such as gold, silver, platinum, and palladium) remain uncharted.

\section{Econometric modeling framework}

\subsection{Asymmetric volatility spillovers}

We introduce a new measure of volatility to assess asymmetries due to negative and positive shocks. Let us assume that the intraday return $r_{t}$ is the $\log$ difference return of the five-minute price, i.e., $r_{t}=100 \times\left(\log P_{t}-\log P_{t-1}\right)$, such that the realized variance $(R V)$ can be defined as

$$
R V=\sum_{i=1}^{n} r_{i}^{2}
$$

Following Barndorff-Nielsen, Kinnebrock, and Shephard (2010), we decompose $R V$ into estimators of realized semivariace (RS) to measure asymmetry due to negative or positive movements in specific volatilities (e.g., bad and good volatility) ${ }^{2}$ The negative and positive realized semi-variances $\left(R S^{-}\right.$and $\left.R S^{+}\right)$are defined as follows:

\footnotetext{
${ }^{2}$ Earlier studies concluded that the realized volatility provides consistent estimates of integrated volatility rather than the proxy of volatility, i.e., absolute returns (Andersen \& Bollerslev, 1998; Andersen et al., 2001, 2003; Barndorff-Nielsen \& Shephard, 2002).
} 

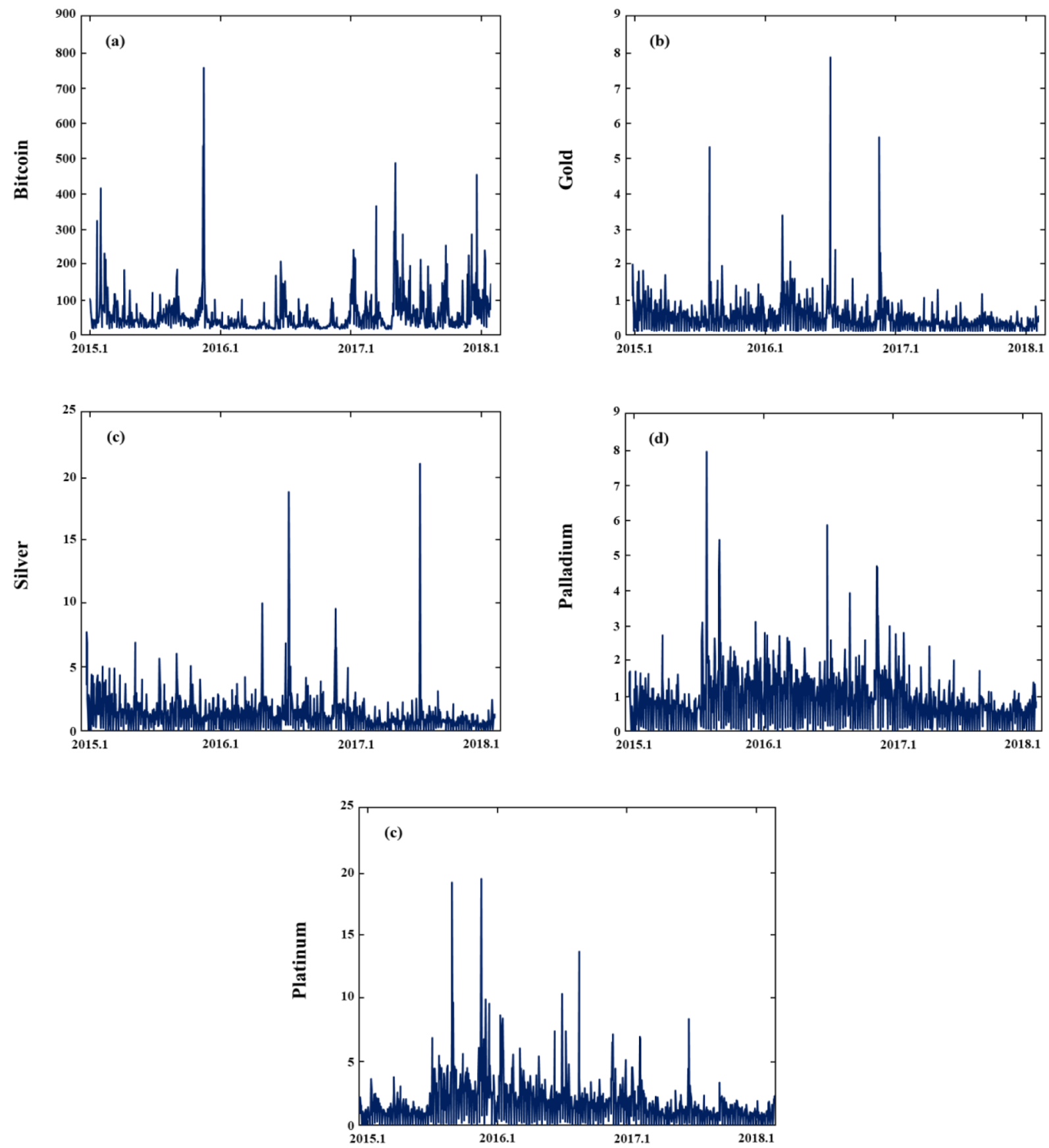

Fig. 1. Dynamics of daily realized volatility Note: This figure shows the realized variances of five assets obtained from five-minute intraday returns. Volatility is computed according to Eq. (1).

$$
\begin{aligned}
& R S^{-}=\sum_{k=1}^{n} r_{k}^{2} \mid\left(r_{k}<0\right) \\
& R S^{+}=\sum_{k=1}^{n} r_{k}^{2} \mid\left(r_{k} \geq 0\right)
\end{aligned}
$$

The summation of negative realized semi-variance, a measure of downside risk $\left(R S^{-}\right)$, and positive realized semi-variance, a measure of upside risk $\left(R S^{+}\right)$, is always equal to the total realized semi-variance $R V$ (i.e., $\mathrm{RV}=R S^{+}+R S^{-}$). Thus, the realized semivariances provide a full picture of the realized variance. 
Table 1

Descriptive statistics for realized volatility, upside semi-volatility, and downside semi-volatility.

\begin{tabular}{|c|c|c|c|c|c|}
\hline & Bitcoin & Gold & Silver & Palladium & Platinum \\
\hline \multicolumn{6}{|c|}{ Panel A: Daily $\sqrt{R V}$} \\
\hline Mean & 5.650 & 0.579 & 1.034 & 0.895 & 1.199 \\
\hline St.dev. & 3.343 & 0.287 & 0.507 & 0.383 & 0.597 \\
\hline Minimum & 0.743 & 0.057 & 0.088 & 0.069 & 0.060 \\
\hline Maximum & 27.651 & 2.821 & 4.614 & 2.855 & 4.465 \\
\hline Skewness & 1.724 & 1.203 & 0.977 & 0.002 & 0.601 \\
\hline Kurtosis & 8.142 & 9.384 & 7.796 & 4.020 & 5.050 \\
\hline Jarque-Bera & $1562^{* * * * *}$ & $1897^{* * * * *}$ & $1093^{* * * * *}$ & $42^{* * * k * k}$ & $230^{* * k \times k}$ \\
\hline \multicolumn{6}{|c|}{ Panel B: Daily $\sqrt{R S^{+}}$} \\
\hline Mean & 3.932 & 0.405 & 0.720 & 0.626 & 0.840 \\
\hline St.dev. & 2.428 & 0.214 & 0.363 & 0.282 & 0.439 \\
\hline Minimum & 0.340 & 0.017 & 0.034 & 0.026 & 0.000 \\
\hline Maximum & 20.100 & 2.296 & 2.857 & 1.828 & 3.201 \\
\hline Skewness & 1.774 & 1.439 & 0.755 & 0.041 & 0.752 \\
\hline Kurtosis & 8.477 & 11.018 & 5.306 & 3.566 & 5.340 \\
\hline Jarque-Bera & $1735^{* \ldots+k}$ & $2957^{* k+k x}$ & $309^{* * * * *}$ & $13^{* * * * *}$ & $299^{* * * * *}$ \\
\hline \multicolumn{6}{|c|}{ Panel B: Daily $\sqrt{R S^{-}}$} \\
\hline Mean & 3.950 & 0.403 & 0.724 & 0.628 & 0.843 \\
\hline St.dev. & 2.478 & 0.214 & 0.390 & 0.284 & 0.434 \\
\hline Minimum & 0.149 & 0.008 & 0.040 & 0.020 & 0.006 \\
\hline Maximum & 18.989 & 2.082 & 3.813 & 2.382 & 3.537 \\
\hline Skewness & 1.789 & 1.282 & 1.421 & 0.238 & 0.730 \\
\hline Kurtosis & 8.453 & 9.134 & 10.215 & 4.835 & 5.791 \\
\hline Jarque-Bera & $1733^{\text {*n+kx }}$ & $1801^{\text {inkik }}$ & $2451^{* * * * *}$ & $146^{\text {****** }}$ & $383^{\text {minktk }}$ \\
\hline
\end{tabular}

Note: This table presents the descriptive statistics of realized volatility and semi-volatility over the sample period, December 15 , 2014 to February 2 , 2018. The Jarque-Bera statistic tests are for the null hypothesis of normality for the distribution of the series. ${ }^{* * * *}$ indicates rejection of the null hypothesis at the $1 \%$ significance level.

Table 2

Total spillovers in daily realized volatility.

\begin{tabular}{|c|c|c|c|c|c|c|}
\hline & Bitcoin & Gold & Silver & Palladium & Platinum & From \\
\hline Bitcoin & 79.62 & 4.99 & 4.26 & 6.27 & 4.85 & 20.4 \\
\hline Gold & 1.09 & 34.26 & 22.33 & 25.08 & 17.24 & 65.7 \\
\hline Silver & 1.33 & 22.95 & 34.99 & 23.75 & 16.98 & 65 \\
\hline Palladium & 1.87 & 23.03 & 21.31 & 30.98 & 22.81 & 69 \\
\hline Platinum & 2.08 & 17.59 & 17.16 & 25.77 & 37.4 & 62.6 \\
\hline To & 6.4 & 68.6 & 65.1 & 80.9 & 61.9 & 282.8 \\
\hline All & 86 & 102.8 & 100 & 111.9 & 99.3 & Total: $56.60 \%$ \\
\hline Net & -14 & 2.9 & 0.1 & 11.9 & -0.7 & \\
\hline Conclusion & Net-recipient & Net-contributor & Neutral & Net-contributor & Neutral & \\
\hline
\end{tabular}

Note: As determined by the Schwarz information criterion, the underlying variance decomposition is based on a daily VAR of order 4, identified using a generalized VAR spillover framework.

To account for the intensity of good and bad volatility, this study distinguishes between the negative semi-variance $R_{t}^{-}=\left(R_{i t}^{-}, \ldots, R S_{n t}^{-}\right)^{\prime}$ and the positive semi-variance $R S_{t}^{+}=\left(R S_{i t}^{+}, \ldots, R_{n t}^{+}\right)^{\prime}$ in the total volatility spillovers, denoted by $R V_{t}=\left(R V_{i t}, \ldots, R V_{n t}\right)^{\prime}$. To this end, we adopt the Diebold and Yilmaz (2012) methodology, which follows directly from the variance decomposition associated with an $\mathrm{N}$-variable vector autoregression fitted to volatility. An $\mathrm{N}$-dimensional vector of realized variance, $R V_{t}=\left(R V_{i t}, \ldots, R V_{n t}\right)^{\prime}$ in $\mathrm{N}$ different markets, is defined as a covariance stationary VAR(p):

$$
R V_{t}=\sum_{i=1}^{P} \Psi_{i} R V_{t-1}+\varepsilon_{t}
$$

where $\Psi_{i}$ are $\mathrm{N} \times \mathrm{N}$ autoregressive coefficient matrices and $\varepsilon_{t}$ is a vector of error terms that are assumed to be serially uncorrelated. As the above VAR process is assumed to be covariance stationary, a moving average representation can be written as $R V_{t}=\sum_{i=0}^{\infty} \Theta_{i} \varepsilon_{t-i}$, where the $\mathrm{N} \times \mathrm{N}$ coefficient matrices $\Theta_{j}$ are obtained from the recursion $\Theta_{i}=\sum_{j=1}^{P} \Psi_{j} \Theta_{i-j}$, with $\Theta_{0}=I_{N}$ and $\Theta_{i}=0$ for $\mathrm{i}<0$.

To estimate the asymmetric volatility spillovers, we construct a VAR model (Eq. (4)), but replace the vector of volatilities $R V_{t}=\left(R V_{i t}, \ldots, R V_{n t}\right)^{\prime}$ with a $2 N$ dimensional vector of negative and positive semi-variances $R S_{t}=\left(R_{i t}^{+}, \ldots, R_{m t}^{+}, R S_{i t}^{-}, \ldots, R_{n t}^{-}\right)^{\prime}$. The elements of the $2 \mathrm{~N} \times 2 \mathrm{NH}$-step-ahead generalized forecast error variance then has the form 


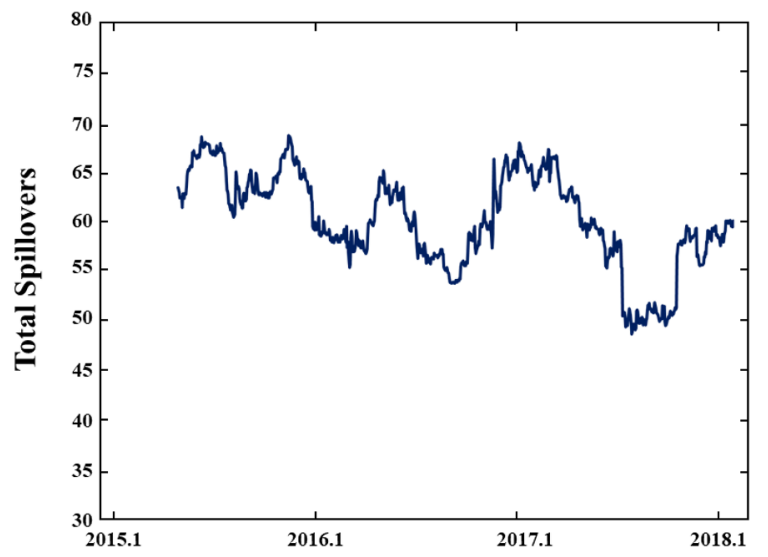

Fig. 2. Total volatility spillover of five assets Notes: The dynamics of total spillovers are calculated using rolling-sample analysis with 100-day rolling windows.

$$
c_{i j}^{g}(H)=\frac{\sigma_{j j}^{-1} \sum_{h=0}^{H-1}\left(e_{i}^{\prime} \Theta_{h} \Sigma e_{j}\right)^{2}}{\sum_{h=0}^{H-1}\left(e_{i}^{\prime} \Theta_{h} \Sigma \Theta_{h}^{\prime} e_{i}\right)}, \quad \mathrm{i}, \mathrm{j}=1, \cdots, 2 \mathrm{~N}
$$

where the covariance matrix of errors in the non-orthogonalized VAR is represented by $\Sigma$. $\sigma_{j j}$ denotes the standard deviation of the error term of the $j^{\text {th }}$ equation, and $e_{i}$ is a $2 N \times 1$ vector, which takes one as the $i^{\text {th }}$ element, and zero otherwise. Finally, $\Theta_{h}$ is the coefficient matrix, which multiplies the $h$-lagged error in the infinite moving-average representation of non-orthogonalized VAR.

\subsection{Directional spillover asymmetry measure}

To quantify the asymmetry volatility spillover, we apply realized semi-variances to obtain more accurate information about spillover behavior by defining a directional spillover asymmetry measure. The asymmetry is the difference between the directional volatility spillover coming from a positive or negative semi-variance. Unlike the symmetric directional spillovers in realized volatilities, we consider the elements of the $H$-step-ahead generalized forecast error variance decomposition in Eq. (5) to compute asymmetric directional spillovers. We define directional spillover from market $i$ to all other markets $j$ as

$$
S_{2 N, i \rightarrow *}(H)=\frac{1}{2 N} \sum_{\substack{i=1, i \neq j \\|i-j| \neq N}}^{2 N} c_{j, i}^{g} \times 100, \quad \mathrm{i}, \mathrm{j}=1, \cdots, 2 \mathrm{~N}
$$

Based on the directional spillovers in Eq. (3), we conjecture the asymmetric directional spillovers that determine how the bad- and good-volatility shocks on one market affect the volatility in all other markets. Following Baruník et al. (2017), the net directional asymmetry spillover $(S A M)$ is defined as the difference in the response of all other markets to a bad- or good-volatility shock in market $i$ as follows:

$$
\operatorname{SAM}_{2 N, i \rightarrow *}(H)=S_{2 N, i \rightarrow *}(H)-S_{2 N,(i+N) \rightarrow *}(H), \quad \mathrm{i}, \mathrm{j}=1, \cdots, \mathrm{N}
$$

where $S_{2 N, i \rightarrow *}$ and $S_{2 N,(i+N) \rightarrow *}$ are volatility spillover indices due to positive and negative semi-variances, respectively, using $H$-stepahead forecasting at time $t$. If the $\operatorname{SAM}_{2 N, j \rightarrow *}(H)$ is negative (positive), we observe a strong effect of bad (good) volatility from market $i$ to all other markets $j$. We also use a moving window of 100 days to include the time-varying asymmetric behavior of the volatility spillover.

\subsection{Spillover asymmetry measure}

To further quantify the magnitude of asymmetric volatility spillovers, we define a spillover asymmetry measure $\left(S A M_{2 N}(H)\right)$ as follows:

$$
\operatorname{SAM}_{2 N}(H)=\sum_{i=1}^{N} S_{2 N, i \rightarrow *}(H)-\sum_{i=N+1}^{2 N} S_{2 N,(i+N) \rightarrow *}(H)
$$

The magnitude of $S A M_{2 N}(H)$ indicates the degree of asymmetry in spillover due to $R S_{t}^{-}$and $R S_{t}^{+}$. When the bad (good) volatility of $R S_{t}^{-}\left(R S_{t}^{+}\right)$dominates the good (bad) volatility of $R S_{t}^{+}\left(R S_{t}^{+}\right), S A M_{2 N}(H)$ is negative (positive). However, if the spillover from $R S_{t}^{-}$and $R S_{t}^{+}$are equal, $S A M_{2 N}(H)$ takes a value of zero, which indicates that there is no spillover symmetry. To test the null hypothesis of symmetric connectedness $\left(\operatorname{SAM}_{2 N}(H)=0\right)$, we use the bootstrap confidence approach of Baruník, Kočcenda, and Vácha (2016).

\subsection{Network connectedness in asymmetry volatility}

Diebold and Yilmaz $(2014,2016)$ propose a network topology of all market connectedness and illustrate the variance 

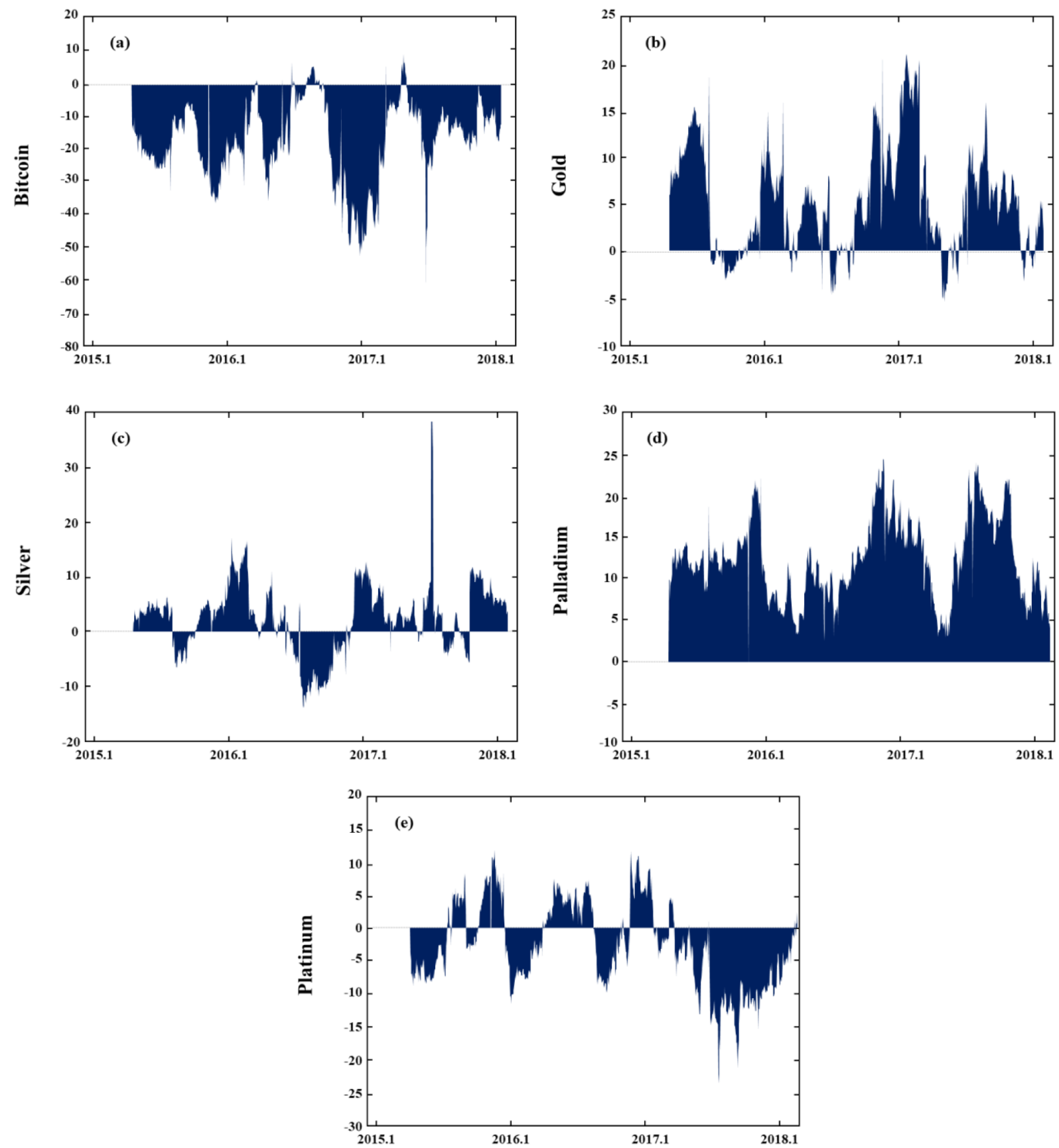

Fig. 3. Net directional spillovers in daily realized volatility Note: Positive values indicate that the asset is a volatility transmitter to other markets, whereas negative values indicate that the asset is a volatility recipient from other markets.

decomposition matrix as the adjacency matrix of a weighted directed network. The elements of the adjacency matrix represent our pairwise directional connectedness, $S_{2 N, i \leftarrow j}(H)$. The sum of the rows (node in degrees) is the total directional connectedness "From," $S_{2 N, i \leftarrow *}(H)$; and the sum of the columns (node out-degrees) is the total directional connectedness "To," $S_{2 N, i \rightarrow *}(H)$.

\section{Data and preliminary analysis}

In our analysis, we examine volatility spillover and its asymmetries between BTC and four major precious metals (gold, silver, palladium, and platinum). In this context, we generate daily realized semi-volatility based on high-frequency five-minute returns over the period January 15, 2014 to February 2, 2018. With the availability of high-frequency data, recent studies use five-minute highfrequency data for estimating realized volatility to eliminate the trade-off between accuracy and market microstructure noise (due to 
Table 3

Asymmetric directional volatility spillover in semi-variances $R S^{+}$and. $R S^{-}$

\begin{tabular}{|c|c|c|c|c|c|c|c|c|c|c|c|c|}
\hline & & & & $R S^{+}$ & & & & & $R S^{-}$ & & & \\
\hline & & BTC & Gold & Silver & Palladium & Platinum & BTC & Gold & Silver & Palladium & Platinum & From \\
\hline \multirow{5}{*}{$R S^{+}$} & BTC & 48.07 & 3.03 & 2.75 & 3.48 & 2.48 & 27.93 & 2.91 & 2.44 & 3.73 & 3.18 & 51.9 \\
\hline & Gold & 0.7 & 21.23 & 14.37 & 14.9 & 9.27 & 1.22 & 11.57 & 7.81 & 10.23 & 8.71 & 78.8 \\
\hline & Silver & 0.85 & 13.98 & 20.98 & 13.82 & 9.22 & 1.29 & 8.98 & 12.12 & 10.29 & 8.46 & 79 \\
\hline & Palladium & 1.12 & 13.05 & 12.52 & 18.44 & 12.29 & 1.8 & 9.33 & 8.37 & 12.34 & 10.74 & 81.6 \\
\hline & Platinum & 1.19 & 9.17 & 9.52 & 14.06 & 22 & 1.85 & 7.81 & 7.26 & 11.41 & 15.73 & 78 \\
\hline \multirow{7}{*}{$R S^{-}$} & BTC & 26.69 & 3.17 & 3.17 & 4.54 & 3.33 & 44.71 & 3.2 & 2.85 & 4.39 & 3.94 & 55.3 \\
\hline & Gold & 0.57 & 11.29 & 9.15 & 10.46 & 7.57 & 1.01 & 21.29 & 13.59 & 15.32 & 9.74 & 78.7 \\
\hline & Silver & 0.74 & 7.98 & 13 & 9.8 & 7.4 & 1.16 & 14.1 & 21.79 & 14.28 & 9.76 & 78.2 \\
\hline & Palladium & 1.03 & 8.8 & 9.27 & 12.19 & 9.73 & 1.49 & 13.67 & 12.24 & 18.72 & 12.85 & 81.3 \\
\hline & Platinum & 1.23 & 8.12 & 8.35 & 11.63 & 14.34 & 1.7 & 9.36 & 9.19 & 14.14 & 21.95 & 78.1 \\
\hline & TO & 34.1 & 78.6 & 82.1 & 94.9 & 75.6 & 39.4 & 80.9 & 75.9 & 96.1 & 83.1 & 740.8 \\
\hline & ALL & 82.2 & 99.8 & 103.1 & 113.3 & 97.6 & 84.2 & 102.2 & 97.7 & 114.9 & 105.1 & Total: $\mathbf{7 4 . 1 0 \%}$ \\
\hline
\end{tabular}

The bold (diagonal) values are the own-spillover effects.

the bid-ask bounce, asynchronous trading, infrequent trading, and price discreteness) (Kumar, 2017; Bissoondoyal-Bheenick, Brooks, \& Do, 2019; Horpestada, Lyócsa, Molnára, \& Olsen, 2019; Luo \& Wang, 2019; Xu, Ma, \& Zhang, 2019).

Note that positive (negative) returns are associated with good (bad) news of Bitcoin and the four precious metals. Each sample has 978 daily realized volatility for the sample period, with 234,306 observations of 5-min interval data available for the analysis. The tick data were obtained from Tick Data, Inc. In order to prevent estimation bias that may be caused by low trading activity on the market, we exclude weekends and holidays, as well as the periods December 24 to 26 and December 21 to January 2.

Fig. 1 shows the dynamics of daily realized volatility from 2014 to 2018 . We observe that, for daily realized volatility, major peaks emerge in the 2015-2016 sub-period. The peaks result from irrational responses on the part of investors (e.g., panic and herd behavior). Investor reactions were strong following both good and bad news.

Table 1 presents the descriptive statistics for the estimated realized variances, upside semi-volatility, and downside semi-volatility. Panel A shows that BTC has the highest mean, as well as the highest standard deviation, of realized variance. The distributions of realized measures for all series exhibit positive skewness, which means that most of the values are lower than the mean. For all distributions of realized measures, the kurtoses were substantially different from 3 , which is the kurtosis of a univariate normal distribution, indicating high peaks and fat tails (leptokurtic). Therefore, based on these two statistical measures, we can conclude that none of the distributions of realized measures is normally distributed, which is also confirmed by the Jarque-Bera statistics. The difference between the means in Panels B and C is negligible, so we may conclude that both types of semi-volatility contribute equally to the realized variance.

\section{Empirical analysis}

This section presents and discusses the estimated results of the volatility spillover effect between the BTC and precious metals markets. The empirical results are divided into three subsections. In the first subsection, we estimate the dynamic spillovers and show the important property of volatility spillover between the BTC and precious metals markets. Second, we examine the asymmetry in semi-volatility transmission by capturing the asymmetric behavior of investors in relation to downside and upside risk. The last section explores the connectedness network to determine the net transmitter or net recipient of asymmetric volatility.

\subsection{Dynamic of volatility spillover: statistical analysis}

The total and net realized volatility spillover index between BTC and precious metals markets are reported in Table 2. The lowerright corner shows that the total spillover reaches $56.6 \%$, implying a high level of volatility spillover between BTC and precious metals markets. More precisely, across our entire sample, $56.6 \%$ of the volatility forecast error variance in all five markets comes from spillovers. As regards the directional spillovers transmitted "To", palladium is the highest contributor to other markets (80.9\%), followed by gold $(68.6 \%)$, silver $(65.1 \%)$, and platinum $(61.9 \%)$. The result indicates that palladium is the market that investors should be cautious of since it is the main source of volatility spillover shock to other precious metals. Both silver and platinum are neutral in terms of spillover contribution, with zero net values. Interestingly, BTC contributes only $6.4 \%$ of volatility spillover to precious metals markets and receives $20.4 \%$ of its volatility spillover from its counterpart market. In terms of net spillovers ("To"-"From"), palladium is the largest net contributor of spillovers (11.9\%), followed by gold (2.9\%), while BTC is the largest net recipient of spillovers $(-14 \%)$. This result indicates that BTC has a much lower impact than precious metals. In fact, it contributes only $1.09 \%$ and $1.33 \%$ to the forecast error variance of gold and silver, respectively, whereas gold contributes $22.95 \%$ to that of silver. This result indicates that silver and palladium act as price discovery tools for gold. On the other hand, BTC provides greater diversification benefits than precious metals.

These findings accord with the results of the spillover tests of Corbet et al. (2018), albeit with different sample periods and data 


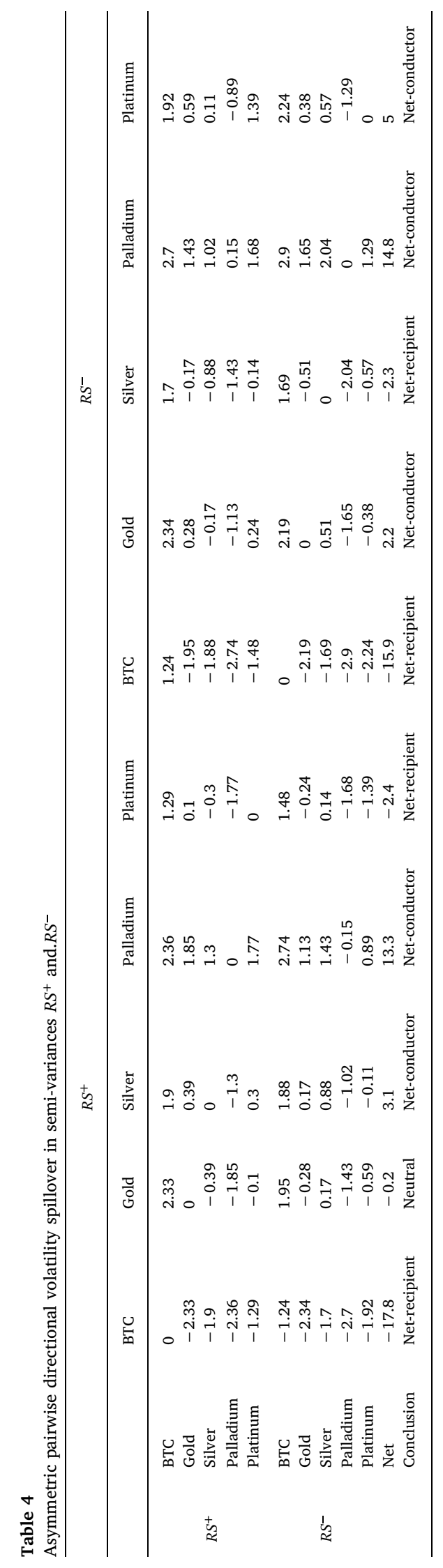




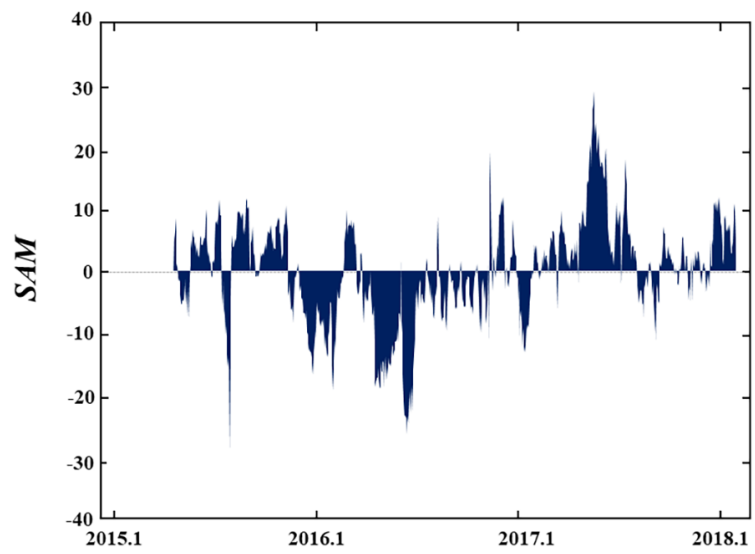

Fig. 4. Spillover asymmetry measure: $S A M$. Note: This figure shows the magnitude of spillover asymmetry using the rolling-sample approach across five assets. Positive (negative) values indicate that spillovers coming from $R S^{+}$are larger (smaller) than those from $R S^{-}$.

frequencies. Their analysis based on Diebold and Yilmaz (2012) generalized variance decomposition methodology reveals little connectedness between cryptocurrency markets (Bitcoin along with Litecoin and Ripple) and other financial markets (e.g., gold, bond FX, SP 500, VIX, and GSCI). Their findings suggest-as does this paper, too-that Bitcoin can be an effective portfolio diversifier and offer safe haven properties for investors.

\subsection{Dynamics of volatility spillover: a graphical analysis}

Although the full-sample spillover tables and indexes provide a useful summary of "average" behavior, they do not show the changes taking place during our sample period. Fig. 2 plots the time-varying total volatility spillover index between BTC and precious metals, obtained using a dynamic rolling-sample analysis. The graphical evidence illustrates that volatility spillovers vary greatly over time and respond to economic events. Volatility spillovers attained their maximum levels in the 2nd and 4th quarters of 2015. These periods correspond to a slowdown in global economic activity, which was caused by the downturn in emerging economies coupled with the subdued growth in advanced economies and the oil price plunge. The contraction in the Chinese economy as well as the slowdown in the Russian and Brazilian economies accounted for the downward pressure on the global growth rate. Furthermore, among the emerging economies, Eastern Europe and Latin America experienced almost zero growth rates. Among the advanced economies, the ongoing recession in Japan had a substantial impact on the deceleration of the global growth rate.

As time passed, the total volatility spillover index recorded a significant downward movement beginning in 2016, which is most likely related to the monetary policies of advanced economies due to the deteriorated global growth prospects in 2015 . The Bank of Japan preferred a negative policy rate while the European Central Bank announced a strong monetary easing program followed by a policy rate cut. In line with these, the Federal Reserve Board sent signals to the market about its mild monetary tightening. Accordingly, expectations of lower policy rates in advanced economies in the long run might be connected to the increase in risk appetite and decrease in risk premiums of emerging economies, which paved the way for capital flows towards emerging economies in the first quarter of 2016. Similarly, low levels of total volatility spillover were experienced in the third quarter of 2016, chiefly because of global economic growth. Among the advanced economies, the US, the Euro area, the UK, and Japan recorded upward trends in growth rates, with the US and the UK economies growing at a significantly stronger pace than previous periods.

The high levels of total spillover in the last quarter of 2016 and the first quarter of 2017 reflect the fallout of two distinctive events that led to uncertainty over the global growth outlook. One is the Brexit, whose implications for the global economy were still unclear. At the same time, the result of the US presidential election led to great uncertainty about economic policy in the US. These two incidents, which led to some policy responses in other economies through spillover effects, determined the high level of total spillover in the last quarter of 2016 and the first quarter of 2017. Volatility spillovers attained their minimum levels in the third quarter of 2017. The trend coincides with the increasing volume of global trade.

Although we report noteworthy findings on the relationship between the total volatility spillover and specific events (i.e., political and macroeconomic events), we do not address the causal character or direction of relationships in our analyses. Further work on causal modeling techniques could help verify whether economic outlook or political events have an impact on the volatility spillover. An investigation of the causal relationships between those variables is beyond the scope of this study, and is therefore left for future research.

In summary, the volatility spillover index increases and decreases over time. Our interpretation is that periods of financial distress trigger large volatility spillovers in BTC and precious metals markets. The results suggest that investors should modify their portfolio structures accordingly.

Fig. 3 illustrates the time evolution of net volatility spillover for each market in addition to the time-varying rolling analysis of the total volatility spillover. A closer inspection of this figure shows that gold and palladium are net transmitters of risk whereas BTC is a net recipient of shocks from precious metals. Gold plays an important role in financial markets with flight-to-quality in times of 

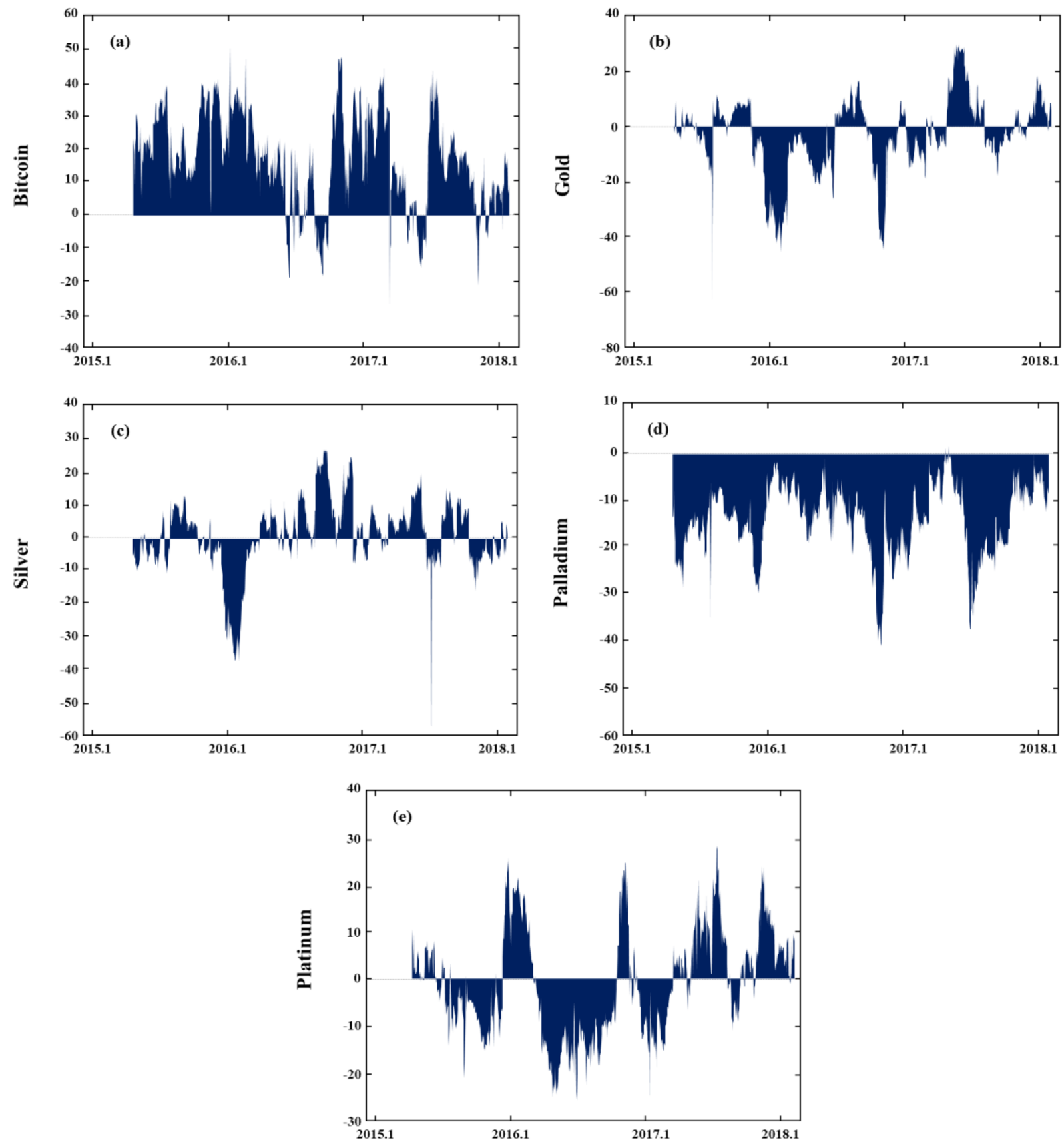

Fig. 5. Net asymmetric directional spillover in semi-variances Note: This figure compares the measure of net asymmetric volatility obtained for the five assets. Positive (negative) values indicate that spillovers coming from $R S^{+}$are larger (smaller) than those from $R S^{-}$.

market distress, is significantly used in central banks' international reserves, and is a store of value, whereas palladium is in strong demand by the automotive sector. Although BTC is often named "new gold," this analysis shows that gold and BTC have different properties. This result may be explained by the small size of BTC market capitalization compared to gold. Both silver and platinum are spillover-neutral over time.

\subsection{Asymmetries in directional volatility spillovers}

We now examine the asymmetric features of directional volatility spillovers between BTC and precious metals, taking into account the different magnitudes of volatility spillovers according to whether the shocks are positive or negative. Table 3 presents the information in a convenient matrix format, enabling us to distinguish the proportions in which good and bad volatilities from 


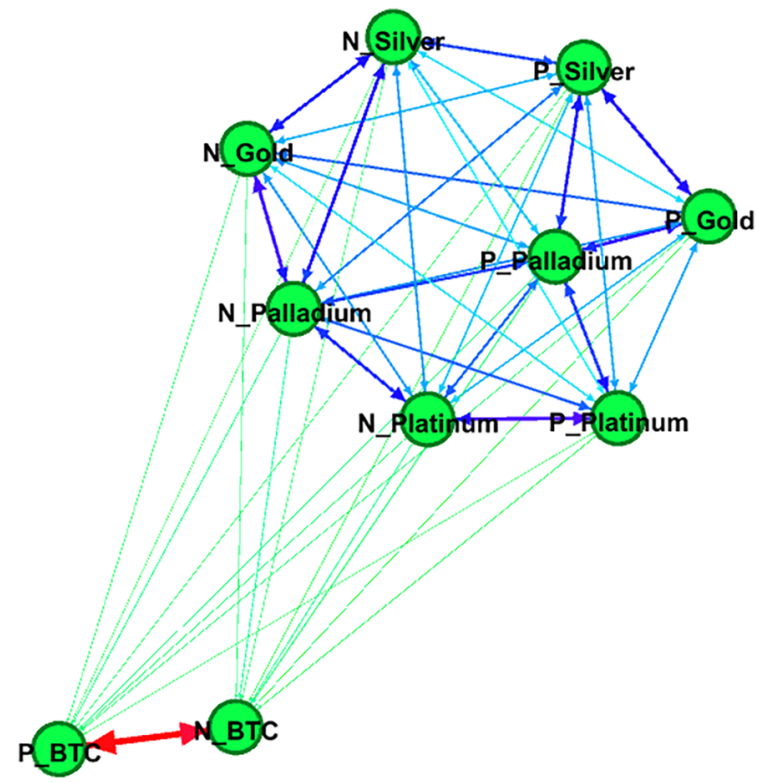

Fig. 6. Pairwise directional network in semi-variances $R S^{+}$and $R S^{-}$. Notes: This figure shows the pairwise directional connectedness within semivariances $R S^{+}$and $R S^{-}$in Table 2 . The edge colors rank the strength of the pairwise directional connectedness, from red (strongest) through blue and light blue to green (weakest). The thickness of the edge arrow indicates the strength of the pairwise directional connectedness. Positive semivariances are indicated by P_BTC (BTC), P_Gold, P_Silver, P_Palladium, and P_Platinum, whereas negative semi-variances are indicated by N_BTC (BTC), N_Gold, N_Silver, N_Palladium, and N_Platinum. (For interpretation of the references to color in this figure legend, the reader is referred to the web version of this article.)

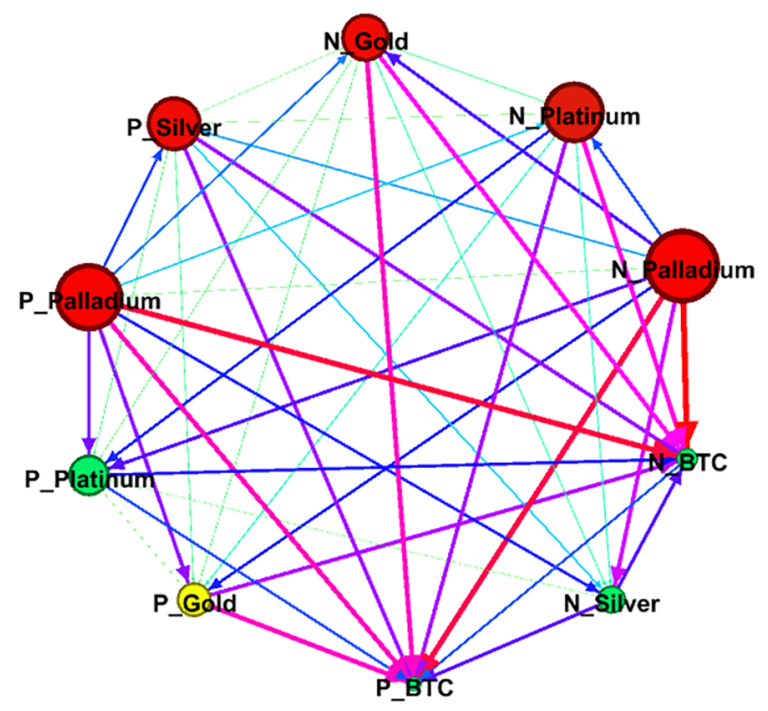

Fig. 7. Net-pairwise directional network in semi-variances $R S^{+}$and $R S^{-}$. Notes: This figure shows the net-pairwise directional connectedness within semi-variances $R S^{+}$and $R S^{-}$in Table 3 . The size of the node shows the magnitude of the net-pairwise directional connectedness, and the colors of the nodes range from red (transmitter) to yellow and green (receiver). The edge colors rank the strength of the net-pairwise directional connectedness, from red (strongest) through magenta and blue to light blue (weakest). See the notes for Fig. 6. (For interpretation of the references to color in this figure legend, the reader is referred to the web version of this article.)

individual assets propagate across markets resulting in positive and negative spillovers that eventually translate into the volatilities of the assets under research. The interpretations of the figures are the same as in Table 2; for this reason, we have not interpreted them here. Positive spillovers are the least-pronounced for BTC, which means that the spillovers of positive shocks transmitted from BTC to precious metals are relatively small. Differentiating between positive and negative shocks provides useful and complete information on volatility spillovers to generate more accurate inputs for portfolio risk management. Note that the spillover index is more pronounced for negative volatility, supporting the leverage effect hypothesis. 
Table 4 shows how the asymmetries in directional volatility spillovers spread between BTC and precious metals. The results show that BTC (palladium) remains a net recipient (transmitter) of shocks from (to) other markets after accounting for good and bad volatilities. Gold has neutral effects for good volatilities, but is a net contributor of bad volatilities, suggesting asymmetry effects. This result also indicates the appropriateness of our methodology. The risk spillover of the platinum and palladium markets shifts according to whether the volatilities are good or bad.

It is worth noting that Tables 3 and 4 do not reveal time-varying directional asymmetry patterns; the full dynamics are illustrated in Fig. 4. Net bad-volatility spillovers dominate the good-volatility spillovers: negative shocks were driving volatility spillovers in 2016. Brexit and the US election were the most potent contributors of negative spillovers. On the other hand, in 2017, net goodvolatility spillovers dominated bad-volatility spillovers, chiefly due to global economic growth.

Fig. 5 displays the dynamic structure of net asymmetric directional spillover in semi-variances for five assets. Following Baruník et al. (2017), the net directional asymmetry spillover is defined as the difference in the response to bad- and good-volatility shocks from one market to all other markets. BTC heavily transmits net positive spillovers to other assets. In other words, net positive spillovers exhibit a greater impact. The bad volatility of palladium affects the volatility of other assets more than its good volatility, which is most likely a reflection of the deficit in the palladium market for several years. On the other hand, the extent of the net spillover of gold is time dependent. Gold heavily transmitted net negative spillovers to other assets in 2016. The pattern is related to the Brexit vote and the US election. Conversely, the second and last quarters of 2017 witnessed positive spillovers, which coincided with the strengthening of the gold price and certainly heightened with the decline in the US dollar.

\subsection{Connectedness network}

Lastly, we develop the network topology of all market connectedness_following Diebold and Yilmaz (2014, 2016)—and obtain Figs. 6 and 7, which show pairwise directional networks in semi-variances $R S^{+}$and $R S^{-}$and net-pairwise directional networks in semivariances $R S^{+}$and $R S^{-}$, respectively. Fig. 6 plots the risk spillover network diagram. All nodes show the same size and color, which do not indicate any directional power. Only edge color and thickness indicate the strength of the spillover direction. Fig. 6 shows a clear clustering of the precious metals markets, but BTC is quite far away. Moreover, the graphical evidence shows a bi-directional pairwise connectedness across positive and negative semi-variances of precious metals, but the connectedness between positive and negative semi-variances of precious metals and BTC is weak. More interestingly, we observe strong bi-directional connectedness between N_BTC and P_BTC. The weak connectedness between the precious metals and BTC markets validates the role of BTC and precious metals as refuge assets against portfolio risk, implying that they can provide diversification benefits and downside risk reductions.

Fig. 7 shows the direction of the net-pairwise spillover, with different node sizes and colors representing the strength of the spillover. This figure simulates the main results for our dynamic analysis of the net-pairwise directional connectedness and provides a visualization of the complex innovation network among the five markets. We show that P_Palladium, N_Palladium, P_Silver, N_Gold, and N_Platinum (red-colored nodes) are net transmitters of volatility spillovers, while N_BTC, P_BTC, P_Platinum, N_Silver (greencolored nodes), and P_Gold (yellow-colored nodes) are net receivers of, or are neutral to, volatility spillovers from other markets. In particular, both P_Palladium and N_Palladium are the largest transmitters, indicating the dominance of palladium over other precious metals for both good and bad news. Interestingly, due to the thick red arrow from palladium to BTC, N_BTC, and P_BTC import volatility from P_Palladium and N_Palladium, suggesting that palladium is the most influential variable on the good and bad volatility of BTC. Palladium and platinum play an important role in many industries, particularly in the motor industry. Since both white metals can be used for the same function in industrial applications, palladium has been slowly substituted for platinum due to its lower cost compared to platinum. However, these two industrial commodities are scarce-even more so than gold. Despite its rarity, coupled with its growing use in everything from the automotive to the jewelry industry, palladium is cheaper than gold or silver, implying that it is currently undervalued. Our findings emphasize the importance of palladium within portfolios and provide significant policy implications for investors. Because of its limited supply and low liquidity, the palladium market sees more fluctuations than the silver and gold markets. Therefore, although palladium may be less appealing to a casual investor, it provides ample opportunity for investors seeking speculative profit.

\section{Conclusion}

Globalization and financial liberalization have increased the integration between financial markets and decreased opportunities for diversification. This paper examines the relationships between the intraday data of the BTC and precious metals (gold, palladium, platinum, and silver) markets. In our analysis, we use the generalized spillover index and directional spillover measure of Diebold and Yilmaz (2012), Baruník et al. (2017) methodology for measuring directional spillover asymmetry, and Diebold and Yilmaz's (2014, 2016) methodology on the network topology of all market connectedness.

The results show evidence of volatility spillover effects among precious metals and BTC. Moreover, the spillover trend is intensified during slowdowns in global economic activity as well as the Brexit vote and the US presidential election, evidencing financial contagion. Palladium is the largest net contributor of spillovers followed by gold, while BTC is a net recipient of spillovers. On the other hand, we support the evidence of asymmetry in semi-volatility transmission showing that BTC heavily transmits net positive spillovers to other precious metal assets. The bad volatility of palladium influences the volatility of other assets more than its good volatility. The magnitude of the net spillover of gold is time-varying and depends on economic events. Finally, we find the network of connectedness and posit that the good and bad volatilities of palladium have the greatest impact on the good and bad volatilities of BTC. 
These findings have important implications for investors and portfolio managers in terms of diversification benefits among the aforementioned five markets. BTC provides greater diversification benefits than precious metals since BTC has a much lower impact on volatility forecast error variance than precious metals. This information can help market participants diversify their risk through optimal portfolio selection. Furthermore, traders of precious metals and BTC may benefit by considering the identified asymmetries in volatility spillovers. However, Bitcoin still evolves and matures and, hence, requires time to be perceived by investors/traders/ practitioners/portfolio managers as an alternative investment to gold and other precious metals.

Moreover, our findings also have implications for policy makers and regulators concerned about price stability and financial stability. Higher spillover transmissions during periods of slowdown in global economic activity or the Brexit and US election periods have led policy makers to re-formulate their economic policies and revive financial reforms and macroeconomic fundamentals in order to stabilize the financial system. Financial authorities should be able to decide on macro-prudential polices in a timely manner by drawing lessons from such periods and identifying potential sources of contagion and spillover risks that may jeopardize financial stability.

\section{Acknowledgments}

This article is a part of Aylin Aslan's Ph.D. thesis in the Faculty of Business Administration in I.D. Bilkent University. The last author (Sang Hoon Kang) acknowledges receiving financial support from the Ministry of Education of the Republic of Korea and the National Research Foundation of Korea (NRF-2017S1A5A8019204).

\section{Appendix A. Supplementary data}

Supplementary data to this article can be found online at https://doi.org/10.1016/j.najef.2019.101031.

\section{References}

Agyei-Ampomah, S., Gounopoulos, D., \& Mazouz, K. (2014). Does gold offer a better protection against losses in sovereign debt bonds than other metals? Journal of Banking \& Finance, 40, 507-521.

Andersen, T. G., \& Bollerslev, T. (1998). Answering the skeptics: Yes, standard volatility models do provide accurate forecasts. International Economic Review, 39, $885-905$.

Andersen, T. G., Bollerslev, T., Diebold, F. X., \& Labys, P. (2001). The distribution of realized exchange rate volatility. Journal of the American Statistical Association, 96, $42-55$.

Andersen, T. G., Bollerslev, T., Diebold, F. X., \& Labys, P. (2003). Modeling and forecasting realized volatility. Econometrica, 71, 579-625.

Antonakakis, N., \& Kizys, R. (2015). Dynamic spillovers between commodity and currency markets. International Review of Financial Analysis, 41, 303-319.

Anyfantaki, S., Arvanitid, S., Topaloglou, N., 2018. Diversification, integration and cryptocurrency market. Working Papers 244, Bank of Greece.

Aslanidis, N., Bariviera, A. F., \& Martínez-Ibañez, O. (2019). An analysis of cryptocurrencies conditional cross correlations. Finance Research Letters, 31, $130-137$.

Bariviera, A. (2017). The inefficiency of bitcoin revisited: A dynamic approach. Economics Letters, 161, 1-4.

Bariviera, A. F., Zunino, L., \& Rosso, O. A. (2018). An analysis of high-frequency cryptocurrencies prices dynamics using permutation-information-theory quantifiers. Chaos: An Interdisciplinary Journal of Nonlinear Science, 28(7), 075511.

Barndorff-Nielsen, O., Kinnebrock, S., \& Shephard, N. (2010). Volatility and time series econometrics: Essays in Honor of Robert F. Engle, Chapter Measuring Downside RiskRealised Semivariance. Oxford University Press.

Baruník, J., Kočcenda, E., \& Vácha, L. (2016). Asymmetric connectedness on the U.S. stock market: Bad and good volatility spillovers. Journal of Financial Markets, 27, $55-78$.

Baruník, J., Kočcenda, E., \& Vácha, L. (2017). Asymmetric volatility connectedness on the forex market. Journal of International Money and Finance, 77, 39-56.

Batten, J. A., Ciner, C., \& Lucey, B. M. (2015). Which precious metals spill over on which, when and why? Some evidence. Applied Economics Letters, 22, 466-473.

Baur, D., Hong, K., \& Lee, A. (2018). Bitcoin: Medium of exchange or speculative assets? Journal of International Financial Markets, Institutions and Money, 54, 177-189.

Baur, D. G., \& Lucey, B. M. (2010). Is gold a hedge or a safe haven? An analysis of stocks, bonds and gold. Financial Review, 45, $217-229$.

Baur, D. G., \& McDermott, T. K. (2010). Is gold a safe haven? International evidence. Journal of Banking \& Finance, 34, 1886-1898.

Belousova, J., \& Dorfleitner, G. (2012). On the diversification benefits of commodities from the perspective of euro investors. Journal of Banking \& Finance, 36 , $2455-2472$.

Bissoondoyal-Bheenick, E., Brooks, R., \& Do, H. X. (2019). Asymmetric relationship between order imbalance and realized volatility: Evidence from the Australian market. International Review of Economics and Finance, 62, 309-320.

Bouoiyour, J., Selmi, R. (2017). Are Trump and Bitcoin good partners? arXiv:1703.00308 [q-fin.GN].

Bouoiyour, J., Selmi, R., \& Wohar, M. E. (2018). Measuring the response of gold prices to uncertainty: An analysis beyond the mean. Economic Modelling, 75, 105-116.

Bouri, E., Azzi, G., \& Dyhrberg, A. H. (2017). On the return-volatility relationship in the bitcoin market around the price crash of 2013. Economics: The Open-Access. Open-Assessment E-Journal, 11, 1-16.

Bouri, E., Gupta, R., Lahiani, A., \& Shahbaz, M. (2018). Testing for asymmetric nonlinear short- and long-run relationships between Bitcoin, aggregate commodity and gold prices. Resources Policy, 57, 224-235.

Bouri, E., Gupta, R., Lau, C. K. M., Roubaud, D., \& Wang, S. (2018). Bitcoin and global financial stress: A copula-based approach to dependence and causality in the quantiles. The Quarterly Review of Economics and Finance, 69, 297-307.

Bouri, E., Jalkh, N., Molnár, P., \& Roubaud, D. (2017). Bitcoin for energy commodities before and after the December 2013 crash: Diversifier, hedge or safe haven? Applied Economics, 49, 5063-5073.

Bouri, E., Molnár, P., Azzi, G., Roubaud, D., \& Hagfors, L. I. (2017). On the hedge and safe haven properties of Bitcoin: Is it really more than a diversifier? Finance Research Letters, 20, 192-198.

Brière, M., Oosterlinck, K., \& Szafarz, A. (2015). Virtual currency, tangible return: Portfolio diversification with bitcoin. Journal of Asset Management, 16(6), 365-373.

Canh, N. P., Wongchoti, U., Thanh, S. D., \& Thong, N. T. (2019). Systematic risk in cryptocurrency market: Evidence from DCC-MGARCH model. Finance Research Letters, 29, 90-100.

Canover, C. M., Jensen, G. R., Johnsos, R. R., \& Mercer, J. M. (2009). Can precious metals make your portfolio shine? Journal of Investing, 18 , 75-86.

Cheah, E. T., \& Fry, J. (2015). Speculative bubbles in bitcoin markets? An empirical investigation into the fundamental value of bitcoin. Economics Letters, 130, 32-36. Ciaian, P., Rajcaniova, M., \& Kancs, D. A. (2016). The economics of BitCoin price formation. Applied Economics, 48, $1799-1815$.

Corbet, S., Meegan, A., Larkin, C., Lucey, B., \& Yarovaya, L. (2018). Exploring the dynamic relationships between cryptocurrencies and other financial assets. Economics Letters, 165, 28-34. 
Coudert, V., \& Raymond, H. (2011). Gold and financial assets: Are there any safe havens in bear markets. Economics Bulletin, 31, $1613-1622$.

Diebold, F. X., \& Yilmaz, K. (2012). Better to give than to receive: Predictive directional measurement of volatility spillovers. International Journal of Forecasting, 28, 57-66.

Diebold, F. X., \& Yilmaz, K. (2014). On the network topology of variance decompositions: Measuring the connectedness of financial firms. Journal of Econometrics, 182, $119-134$.

Diebold, F. X., \& Yilmaz, K. (2016). Trans-Atlantic equity volatility connectedness: U.S. and European Financial Institutions, 2004-2014. Journal of Financial Econometrics, 14, 81-127.

Draper, P., Faff, R. W., \& Hillier, D. (2006). Do precious metals shine? An investment perspective. Financial Analysts Journal, 62, 98-106.

Dwyer, G. (2015). The economics of Bitcoin and similar private digital currencies. Journal of Financial Stability, 17, 81-91.

Dyhrberg, A. H. (2016). Hedging capabilities of bitcoin. Is it the virtual gold? Finance Research Letters, 16, $139-144$.

Eisl, A., Gasser, S.M., Weinmayer, K., 2015. Caveat emptor: Does Bitcoin improve portfolio diversification? SSRN 2408997. Working Paper.

Fernandez-Perez, A., Frijns, B., \& Tourani-Rad, A. (2017). Precious metals, oil and the exchange rate: Contemporaneous spillovers. Applied Economics, 49, 3863-3879. Gangwal, S. (2016). Analyzing the effects of adding Bitcoin to portfolio. International Journal of Economics and Management Engineering, 10, $3519-3532$.

Glantz, M., \& Kissell, R. (2013). Multi-asset risk modeling: Techniques for a global economy in an electronic and algorithmic Trading. Era. Academic Press.

Guesmi, K., Saadi, S., Abid, I., \& Ftiti, Z. (2019). Portfolio diversification with virtual currency: Evidence from bitcoin. International Review of Financial Analysis, 63 , $431-437$.

Hammoudeh, S., \& Yuan, Y. (2008). Metal volatility in presence of oil and interest rate shocks. Energy Economics, 30, 606-620.

Hillier, D., Draper, P., \& Faff, R. (2006). Do precious metals shine? An investment perspective. Financial Analysts Journal, 62 , $98-106$.

Horpestada, J. B., Lyócsa, Š., Molnára, P., \& Olsen, T. B. (2019). Asymmetric volatility in equity markets around the world. North American Journal of Economics and Finance, 48, 540-554.

Huang, J., Cheng, H., Guo, Y., \& Shao, L. (2012). An empirical research on US dollar, oil and metal prices based on VAR model. Journal of Economic Surveys, 3, 45-49. Jensen, G. R., Johnson, R. R., \& Mercer, J. M. (2002). Tactical asset allocation and commodity futures. Journal of Portfolio Management, 8, $100-111$.

Ji, Q., Bouri, E., Gupta, R., \& Roubaud, D. (2018). Network causality structures among Bitcoin and other financial assets: A directed acyclic graph approach. The Quarterly Review of Economics and Finance, 70, 203-213.

Ji, Q., Bouri, E., Lau, C. K. M., \& Roubaud, D. (2019). Dynamic connectedness and integration in cryptocurrency markets. International Review of Financial Analysis, 63, $257-272$.

Ji, Q., Bouri, E., \& Roubaud, D. (2018). Dynamic network of implied volatility transmission among US equities, strategic commodities, and BRICS equities. International Review of Financial Analysis, 57, 1-12.

Katsiampa, P. (2018). Volatility co-movement between Bitcoin and Ether. Finance Research Letters.. https://doi.org/10.1016/J.FRL.2018.10.005 In Press.

Kristoufek, L. (2013). Bitcoin meets Google Trends and Wikipedia: Quantifying the relationship between phenomena of the internet era. Scientific Reports, 3, 1-7.

Kumar, D. (2017). Realized volatility transmission from crude oil to equity sectors: A study with economic significance analysis. International Review of Economics and Finance, 49, 149-167.

Lucey, B. M., \& Li, S. (2015). What precious metals act as safe havens, and when? Some US evidence. Applied Economics Letters, 22 , 35-45.

Luo, J., \& Wang, S. (2019). The asymmetric high-frequency volatility transmission across international stock markets. Finance Research Letters, 31, $104-109$.

Mensi, W., Hamed Al-Yahyaee, K., \& Kang, S. H. (2017). Time-varying volatility spillovers between stock and precious metal markets with portfolio implications. Resources Policy, 53, 88-102.

Molnár, P., Vagstad, K., Valstad, O., 2015. A bit risky? A comparison between Bitcoin and other assets using an intraday value at risk approach, Working Paper, available at: http://www.diva-portal.org/smash/get/diva2:742882/fulltext01.pdf.

Nadarajah, S., \& Chu, J. (2017). On the inefficiency of Bitcoin. Economics Letters, 150, 6-9.

O'Connor, F. A., Lucey, B. M., Batten, J. A., \& Baur, D. G. (2015). The financial economics of gold-A survey. International Review of Financial Analysis, 41, 186-205.

Peng, Y., Albuquerque, P. H. M., de Camboim, S. J. M., Padula, A. J. A., \& Montenegro, M. R. (2018). The best of two worlds: Forecasting high frequency volatility for cryptocurrencies and traditional currencies with support vector regression. Expert Systems with Applications, 97, 177-192.

Popper, N. (2015). Digital gold: The untold story of Bitcoin. London: Penguin.

Reboredo, J. C., \& Rivera-Castro, M. A. (2014). Can gold hedge and preserve value when the US dollar depreciates? Economic Modelling, 39, 168-173.

Selmi, R., Mensi, W., Hammoudeh S., Bouoiyour, J., 2018. Is bitcoin a hedge, a safe haven or diversifier for oil price movements? a comparison with gold. Energy Economics 74, 787-801.

Sensoy, A. (2018). The inefficiency of Bitcoin revisited: A high-frequency analysis with alternative currencies. Finance Research Letters, $28,68-73$.

Shahzad, F., Xiu, G., Wang, J., \& Shahbaz, M. (2018). An empirical investigation on the adoption of cryptocurrencies among the people of mainland China. Technology in Society, 55, 33-40.

Shahzad, S. J. H., Bouri, E., Roubaud, D., Kristoufek, L., \& Lucey, B. (2019). Is Bitcoin a better safe-haven investment than gold and commodities? International Review of Financial Analysis, 63, 322-330.

Skiadopoulos, G. (2012). Investing in commodities: Popular beliefs and misconceptions. Journal of Asset Management, 13, 77-83.

Urquhart, A. (2016). The inefficiency of bitcoin. Economics Letters, 148, 80-82.

Xu, W., Ma, F., \& Zhang, B. (2019). Asymmetric volatility spillovers between oil and stock markets: Evidence from China and the United States. Energy Economics, 80, 310-320.

Yaya, O. O. S., Tumala, M. M., \& Udomboso, C. G. (2016). Volatility persistence and returns spillovers between oil and gold prices: Analysis before and after the global financial crisis. Resources Policy, 49, 273-281.

Yermack, D. (2014). Is Bitcoin a real currency? An economic appraisal, NBER Working Paper No. w19747, available at: http://www.nber.org/papers/w19747.pdf. 